\title{
Health service use and costs among migrants in an irregular situation: cross- sectional register-based study from a voluntary-based clinic
}

Nina Tjukanov ( $\square$ nina.tjukanov@gmail.com )

Vaasan Yliopisto

Paula Tiittala

Global Clinic

Heli Salmi

Global Clinic

\section{Research article}

Keywords: Immigrant, undocumented, healthcare, entitlements to healthcare, healthcare costs

Posted Date: February 3rd, 2020

DOI: https://doi.org/10.21203/rs.2.22429/v1

License: (c) (i) This work is licensed under a Creative Commons Attribution 4.0 International License. Read Full License

Version of Record: A version of this preprint was published at Journal of Public Health on January 1st, 2021. See the published version at https://doi.org/10.1093/pubmed/fdab382. 


\section{Abstract}

Aim

The increase in immigration to Europe has led to an increasing demand for information about healthcare needs and costs of vulnerable migrant populations, but few data based on actual demand for healthcare services and related costs exist.

\section{Methods}

In this single-centre retrospective register study, we examined the reasons for encounter and diagnoses, service use and costs of healthcare among patients at a voluntary clinic for migrants in an irregular situation in Helsinki, Finland in 2016. ICPC-2 classification and unit costs for primary healthcare in Finland were used as a basis for the cost estimation.

\section{Results}

546 patient visits accounted for 620 ICPC-2 coded reasons for encounter, diagnoses and process codes. The most common health problems were teeth/gum disease (10\%), acute upper respiratory infection (5\%) and oesophageal disease (3\%). Visits seldom led to complementary investigations ( $2 \%)$, follow-up visit to the clinic (5\%) or referral to public healthcare (11\%). The total cost of treatment, excluding dental health costs, was 39547 euros, or 71 euros per visit.

\section{Conclusions}

Migrants in an irregular situation present with a variety of health concerns, the majority of which can be treated in a basic primary healthcare facility. The cost of healthcare was relatively low, as most of the complaints could be treated with simple means. More research is needed to understand the health and cost benefits of extending public healthcare services for migrants in an irregular situation beyond emergency care.

\section{Background}

Following recent increases in migration to Europe, countries with previously limited experience on irregular migration face new challenges when establishing healthcare policies for migrants. Most European countries offer emergency care to everyone [1] but payment policies differ [2]. Some countries recognize the need to provide broader services for vulnerable populations such as children [1].

Although medical practitioners widely agree on the ethical justification, medical and humanitarian necessity and cost-effectiveness of providing at least necessary healthcare for all $[3,4,5]$, proposals on broader entitlements to healthcare services for migrants often raise concerns about burden to the public healthcare system. However, few data based on actual healthcare costs exist to support decisions. Thus, we aimed to explore health problems, service use and costs of healthcare among patients at a voluntary clinic for migrants in an irregular situation in Helsinki, Finland.

\section{Methods}

\section{Study area and setting}

Finland is a high-income country with public health insurance based on residency. Municipalities are responsible for offering health services for their inhabitants. Migrants in an irregular situation, including vulnerable populations such as children and pregnant women, are entitled only to urgent care at their own cost. Health education, preventive care and medication or follow-up for chronic conditions are not provided (Health Care Act 1326/2010 50 §).

The number of migrants in an irregular situation in Finland is estimated at 2000-10 000, with the majority residing in Helsinki capital area. In 2013 , the city of Helsinki, with the population of 635181 [6], decided to extend the level of care beyond emergency care for children and pregnant women in an irregular situation [7].

\section{Global Clinic}

Global Clinic is a voluntary-run free-of-charge walk-in clinic offering anonymous primary healthcare services for migrants in an irregular situation living in the Helsinki capital area. The consultations take place once a week and a phone service operates daily. The multiprofessional team consists of health professionals (physicians, dentists, midwives, nurses, psychologists), lawyers and interpreters.

\section{Study population}

All patient visits to different health professionals (physicians, dentists, nurses, midwives and psychologists) from January 1 to December 31,2016 were included. Information on basic sociodemographic characteristics, reasons for encounter, number of re-encounters, diagnoses, treatment and referral were systematically collected from the clinic's electronic health record (ASTA $®$ ). Visits with missing information on basic characteristics and reasons for encounter and diagnoses were excluded.

\section{Outcomes}

Reasons for encounter and diagnoses were converted to International classification of primary healthcare codes (ICPC-2) [8] by the study physicians (P.T, H.S.). One visit may include several ICPC-2 codes. Causal codes were preferred over a symptom codes and other codes over process and operation codes. 
Healthcare costs were calculated based on ICPC-2 codes using unit costs of primary healthcare services in Finland for 2011 [9]. Correction coefficient $(1,07)$ was used to adjust the inflation from 2011 to 2016 [10]. Dental problems and operation codes were excluded from the total costs due to unavailability of information on operation costs. Costs were categorized to ICPC-2-chapters.

\section{Statistical analyses}

Descriptive statistics were calculated with MS Excel 2016. IBM SPSS Statistics 25 was used to compare means with independent samples t-test and categorical variables with Pearson chi squared. $\mathrm{P}$ values $<0.05$ were considered statistically significant.

\section{Results}

Altogether 556 patient visits to the Global Clinic in 2016 were included in the study (Table 1). Three visits were excluded due to missing information. The mean age was 35 years (range $0-69)$ without statistically significant difference by gender $(p=0.10)$. Children represented $4 \%$ of all visits. Three-fourths of visits represented patients from other EU countries, mainly from Bulgaria and Romania.

Table 1. Basic sociodemographic characteristics of patient visits in the clinic 2016; $n$ (\%). Total $n=556$.

\begin{tabular}{|c|c|}
\hline Age & n (\%) \\
\hline $0-6$ & $5(1)$ \\
\hline $7-16$ & $18(3)$ \\
\hline $17-29$ & $168(30)$ \\
\hline $30-45$ & $212(38)$ \\
\hline $46-65$ & 105 (19) \\
\hline $66-$ & $2(0)$ \\
\hline Age unknown & $46(8)$ \\
\hline Sex & n (\%) \\
\hline Female & $235(42)$ \\
\hline Male & $306(55)$ \\
\hline Sex unknown & $15(3)$ \\
\hline Region of origin & n (\%) \\
\hline Europe & $408(73)$ \\
\hline North-Africa and the Middle East & $28(5)$ \\
\hline Sub-Saharan Africa & $81(15)$ \\
\hline Asia & $15(3)$ \\
\hline America & $4(1)$ \\
\hline Region of origin unknown & $20(4)$ \\
\hline
\end{tabular}


Follow-up visits represented $37 \%(n=203)$ of all visits. Two percent of visits resulted in complementary investigations, $5 \%$ in follow-up visits to the clinic and $11 \%$ in a referral to public healthcare, most often to an emergency department ( $80 \%)$ and to maternal and child health centres (18\%).

In total 620 ICPC-2 codes were registered to 546 visits. Ten visits did not receive any ICPC- 2 code. Twelve percent $(n=64)$ of all visits had more than one ICPC-2 code.

The most common health concerns belonged to digestive (22\%), including dental health problems, musculoskeletal (12\%) or dermatological (11\%) ICPC-2 categories (Figure 1). The three most common ICPC-2 diagnoses were teeth/gum disease (10\%), acute upper respiratory infection (5\%) and oesophageal disease (3\%). No statistically significant differences by gender were observed among these most common health concerns. For women, $17 \%$ of visits were related to pregnancy, childbearing or family planning.

The total cost of care based on 620 ICPC-2 codes was 39547 euros, or 71 euros per visit on average. Digestive, excluding dental health problems, musculoskeletal and dermatological problems represented $41 \%$ of the total costs (Figure 1). For women, $10 \%$ of costs were related to antenatal follow-up.

\section{Discussion}

Our study shows that migrants in an irregular situation have medical complaints covering the whole range of medical specialties. Still, most health problems were amenable to treatment in a very basic healthcare setting. Accordingly, the cost of the treatment would have been relatively low, if the treatment had been provided in public primary healthcare.

Our results are in line with previous studies from European countries reporting varying healthcare needs [11], low incidence of tropical diseases or acute severe infectious diseases such as tuberculosis or HIV [11, 12], frequent encounters for obstetric or gynaecological problems [11], and a surprisingly low incidence of psychiatric conditions [13].

The average cost per visit in Global Clinic was lower than for physician

$s \geq \neq$ ralpracticeencounter $\in F \in l$ and $\in 2016$ [9]. A or $d \in g \rightarrow$ estimates[4] and evnceomactualserviceuse[14] and actualcosts[15], e. healthcare entitlements beyond emergency care is likely to cost less than estimated based on healthcare costs in the general population.

Immigrants in an irregular situation tend to use less healthcare services than they are entitled to [16, 17]. Multiple administrative, economic, language and cultural barriers, and fear of authorities, decrease the accessibility of services. This was also seen in our study, where pregnancy was a common reason for encounter even if most of the women were entitled to public free-of-charge maternity care. Our study suggests that in vulnerable populations, access to care should be encouraged by low-threshold services, sufficient information in relevant languages, and establishing trust.

The observed relatively low number of children among migrant patients in an irregular situation seen also in Denmark [11] can reflect the age distribution of the irregular migrant population in Nordic countries, or lower barriers to public healthcare compared to adults.

As the demographics of migrants in an irregular situation in the study area are unknown, we were unable to make comparisons with the general population. In addition, we were unable to include costs for emergency healthcare given at other healthcare facilities. On the other hand, as we used unit costs even for revisits and visits with multiple complaints, we may have overestimated the costs.

\section{Conclusions}

Even without the possibility to compare the healthcare costs in the general population, we feel confident to conclude that the costs of primary-level nonemergency public healthcare to migrants in an irregular situation is low, and most of the complaints can be treated with very simple means. More research is needed to understand the health and cost benefits of extending public healthcare services for migrants in an irregular situation beyond emergency care.

\section{Declarations}

\section{ETHICS APPROVAL AND CONSENT TO PARTICIPATE}

The study protocol was approved by the ethics committee of Helsinki Deaconess Institute in fall 2013 and updated in 2016.

\section{CONSENT FOR PUBLICATION}

Not applicable.

\section{AVAILABILITY OF DATA AND MATERIALS}

These data are not publicly available due to protection of privacy of a vulnerable population.

\section{COMPETING INTERESTS}

The authors declare that they have no competing interests.

\section{FUNDING}

Loading [MathJax]/jax/output/CommonHTML/fonts/TeX/fontdata.js 
Funding Centre for Social Welfare and Health Organisations (STEA) is responsible for the costs resulting from submitting the manuscript. Nevertheless, STEA has not involved conducting the study by no means.

\section{AUTHORS' CONTRIBUTIONS}

All the authors designed the study together.

N.T. collected the data, carried out the data analyses, was mainly responsible for the writing of the manuscript, and drew the figures and tables.

P.T. and H.S. conceptualized the study, coded the diagnoses after systematically reviewing the patient records, and drafted and critically reviewed the manuscript.

\section{ACKNOWLEDGEMENTS}

We would like to express our sincerest thanks to Heini Salo and Kaisa Mölläri from National Institute for Health and Welfare for their technical help in different phases of the research. We are grateful for all the voluntary doctors and nurses at the clinic for their work.

\section{References}

1. Suess A et al. The right of access to health care for undocumented migrants: a revision of comparative analysis in the European context. European Journal of Public Health 2014; 24(5): 712-720.

2. Cuadra CB. Right of access to health care for undocumented migrants in EU: a comparative study of national policies. European Journal of Public Health 2012; 22(2): 267-271.

3. Andre JM and Azzedine F. Access to healthcare for undocumented migrants in France: a critical examination of State Medical Assistance. Public Health Rev 2016; 37: 5.

4. FRA - European Union Agency for Fundamental Rights. Cost of exclusion from healthcare: the case of migrants in an irregular situation. Report, 2015. Luxembourg: Publications Office of the European Union.

5. Heras-Mosteiro J, Sanz-Barbero B and Otero-Garcia L. Health care austerity measures in times of crisis: the perspectives of primary health care physicians in Madrid, Spain. Int J Health Serv 2016; 46(2): 283-299.

6. Statistics Finland. Statistics Finland`s PX-Web databases: Population 31 Dec by Year, Area and Information, http://pxnet2.stat.fi/PXWeb/pxweb/en/StatFin/StatFin_vrm_vaerak/statfin_vaerak_pxt_028.px/table/tableViewLayout2/?rxid=902d167a-89cd-46998c9e-59ec6d3f943a (2018, accessed 2 January 2019).

7. City of Helsinki. 26.11.2013 § 404, https://dev.hel.fi/paatokset/asia/hel-2012-013136/khs-2013-44/ (2013, accessed 24 January 2018).

8. Wonca. International Classification of Primary Care, https://www.globalfamilydoctor.com/site/DefaultSite/filesystem/documents/Groups/WICC/International\%20Classification\%20of\%20Primary\%20Care\%2 (2016, accessed 20 January 2019).

9. Kapiainen S, Väisänen A and Haula T. Terveyden- ja sosiaalihuollon yksikkökustannukset Suomessa vuonna 2011 [The unit costs of health and social care in Finland in 2011]. Report no 3, National Institute for Health and Welfare, Finland, 2014.

10. Statistics Finland. Statistics Finland's PxWeb databases: StatFin, https://pxnet2.stat.fi/PXWeb/pxweb/fi/StatFin/ (2017, accessed 20 June 2019).

11. Ehmsen BK et al. Undocumented migrants have diverse health problems. Danish Medical Journal 2014; 61(9).

12. Kaoutar B, Mathieu-zahzam J and Lebas P. Chauvin La santé des migrants consultant la policlinique Baudelaire de l'hôpital Saint-Antoine à Paris, France. Bull. Soc Pathol. Exot. 2012; 105(2): 86-94.

13. Baglio G et al. Gli immigrati irregolari: cosa sappiamo della loro salute? [Undocumented immigrants: what do we know about their health?] Epidemiol Prev2017; 41: 57-63.

14. Gimeno-Feliu LA et al. Global healthcare use by immigrants in Spain according to morbidity burden, area of origin, and length of stay. BMC Public Health 2016; $16: 450$.

15. Statskontoret. Vård till papperslösa: En uppföljning av lagen om vård till personer som vistas i Sverige utan tillstånd. Report no 10 , Sverige, 2015.

16. Biswas et al. Access to healthcare and alternative health-seeking strategies among undocumented migrants in Denmark. BMC Public Health 2011; 11 : 560.

17. O'Donnell CA et al. Reducing the health care burden for marginalised migrants: The potential role for primary care in Europe. Health Policy 2016; 120 : 495-508.

\section{Figures}




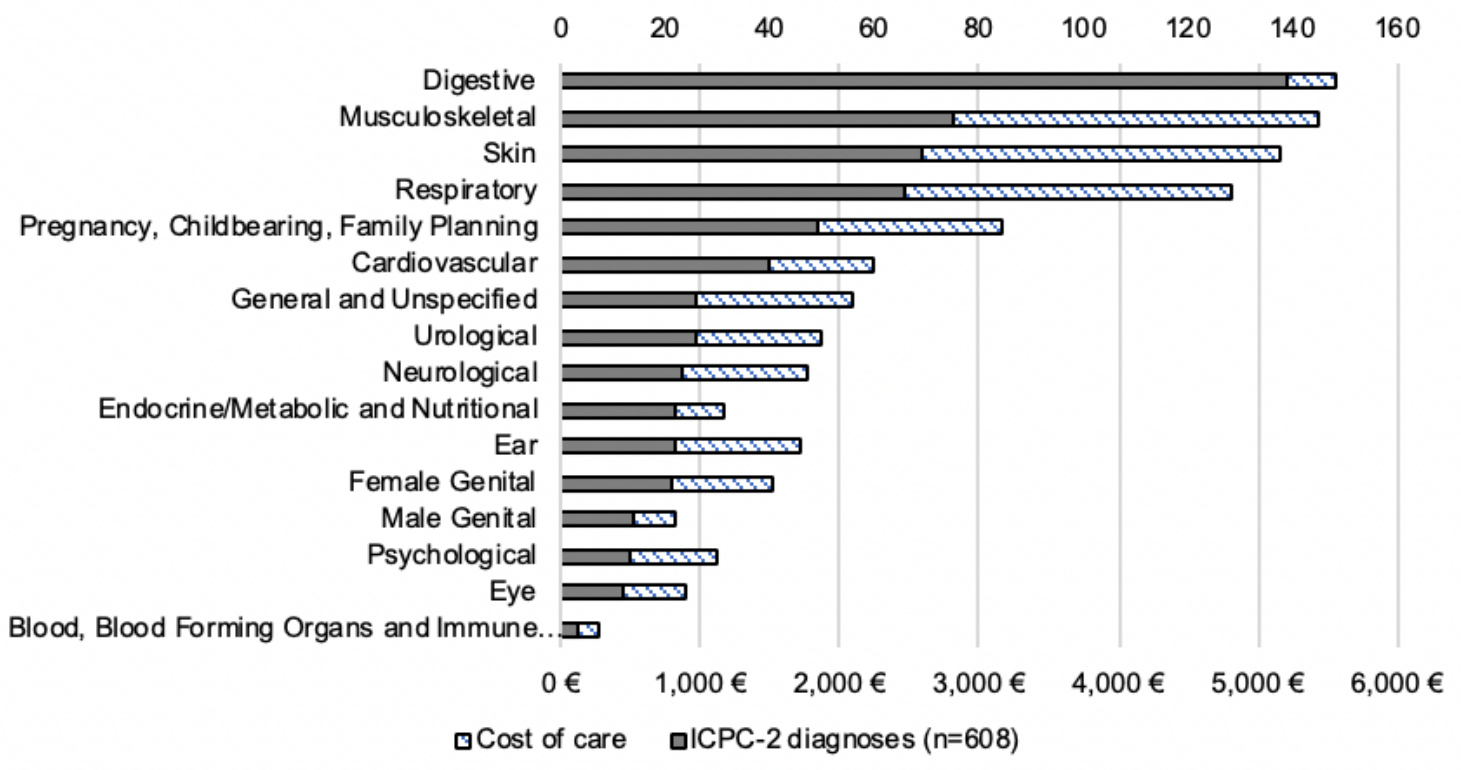

Figure 1

ICPC-2 codes $(n=620)$ and costs categorized to ICPC-2 (International Classification of Primary Care) chapters. 